\title{
GESTÃO ABEPSS 2002-2004 - QUEM É DE LUTA AVANÇA!
}

\section{RESUMO}

\author{
Jussara Maria Rosa Mendes ${ }^{1}$ \\ Vera Maria Nogueira ${ }^{2}$ \\ Regina Célia Miotto ${ }^{3}$ \\ Berenice Rojas Couto ${ }^{4}$
}

Este artigo enfoca o papel da Associação Brasileira de Ensino e Pesquisa em Serviço Social - ABEPSS - vem desempenhando no âmbito da formação profissional, a partir das novas exigências postas ao ensino superior nos processos de globalização. Destaca a importância das Diretrizes Gerais para o Curso de Serviço Social na consolidação do Projeto Profissional no Brasil.

PALAVRAS-CHAVES: Formação profissional, Diretrizes Curriculares, ABEPSS, Projeto Profissional.

“Se as coisas são inatingíveis... ora! Não é motivo para não querê-las... Que tristes os caminhos, se não fora à mágica presença das estrelas”.

Das utopias - Mário Quintana

O trabalho das entidades representativas da profissão há muito tempo tem contribuído para a formulação da identidade da profissão na sociedade brasileira. Portanto, é um processo que está sedimentado nas lutas dos profissionais, dos docentes, discentes e das entidades que representam o Serviço Social. Assim, também as demandas que são levadas a cabo por uma diretoria são construções históricas que tem apontado, nessa época

\footnotetext{
${ }^{1}$ Professora adjunta da Faculdade e do Programa de Pós-Graduação em Serviço Social da PUCRS /Brasil Presidente da Associação Brasileira de Ensino e Pesquisa em Serviço Social/ ABEPSS na Gestão 2002-2004.

${ }^{2}$ Professora do curso de Serviço Social da UFSC/ Brasil. Coordenadora da Graduação na ABEPSS na Gestão 2002-2004.

${ }^{3}$ Professora do curso de Serviço Social da UFSC/ Brasil. Coordenadora da Pós-Graduação na ABEPSS na Gestão 2002-2004.

${ }^{4}$ Professora adjunta da Faculdade e do Programa de Pós-Graduação em Serviço Social da PUCRS/Brasil Coordenadora do PPGSS/PCRS, Membro da diretoria da ABEPSS na Gestão 2002-2004.

\begin{tabular}{llllll}
\hline Serviço Social \& Saúde & Campinas & v. 4 & n. 4 & p. 1-156 & Maio 2005
\end{tabular}
}


presente, para a consolidação do projeto ético político da profissão. Com a clareza desse desafio, a gestão da ABEPSS de 2002-2004, consolidou seus propósitos em uma plataforma que foi denominada, conjuntamente, de "quem é de luta avança”. Nela, os princípios norteadores de um trabalho integrado com as demais entidades da categoria e dos estudantes apresentou-se como eixo essencial. Tornou-se necessário nesse processo, ter-se a clareza de que a atual conjuntura impõe avanços e entraves ao projeto de formação profissional que se constrói desde a definição das diretrizes curriculares, em 1982. Retomar o processo de consolidação das diretrizes, enfrentando seus desafios contemporâneos foi à tarefa colocada como fundante ao trabalho dessa gestão.

Buscar desvendar as contradições em que constituíam essa formação foi o primeiro passo, para o qual nos valemos das produções importantes e da trajetória da própria ABEPSS, retomada a partir de suas publicações.

O Serviço Social Brasileiro redimensionou-se e renovou-se, e essa afirmação nos exige desvendar a profissão e também elucidar a herança cultural a partir da qual se constrói o discurso profissional sobre o exercício e a formação do Assistente Social. Na divisão sócio-técnica do trabalho, afirma-se como uma profissão na sociedade, dotada de uma dimensão teórico-metodológica e técnico-operativa que intrinsecamente relacionadas norteiam-se por fundamentos ético-políticos. Assim, o Serviço Social vem respaldando seu trabalho, as sistematizações realizadas sobre seu processo de trabalho e temas que o permeiam e demais saberes que constrói, nutrindo-se do acervo intelectual e cultural herdado, fundamentalmente, do pensamento social que se desenvolveu na modernidade. São do mesmo modo importantes nesse processo as contribuições de pesquisas, realizadas no universo do Serviço Social, relativas ao conhecimento dos processos sociais.

Na década de 1980, afirma-se a maioridade acadêmica dos Assistentes Sociais, impulsionada pela pós-graduação, pelo crescimento do mercado editorial e por uma fértil produção que ultrapassa os muros profissionais, permitindo uma interlocução teórica, no mesmo patamar, com áreas conexas de maior tradição na pesquisa social (IAMAMOTO, 2003).

\begin{tabular}{llllll}
\hline Serviço Social \& Saúde & Campinas & v. 4 & n. 4 & p. 1-156 & Maio 2005
\end{tabular} 
A partir da produção teórica, qualificada e acumulada nas últimas décadas, traçou-se um forte embate com o conservadorismo no que se refere à interpretação teóricometodológica do Serviço Social, buscando adequar criticamente a profissão, às exigências do seu tempo.

No que se refere à dimensão da ética, pode-se afirmar que houve um avanço radical. Através do Código de Ética de 1993 constituíram-se, democraticamente, direitos e deveres dos Assistentes Sociais, segundo princípios e valores humanistas, guias para o exercício profissional cotidiano. Destacam-se no campo ético-político o reconhecimento da liberdade como valor ético central, e conseqüentemente o reconhecimento da autonomia, da emancipação e da plena expansão dos indivíduos sociais e de seus direitos, como elementos necessários a sua consecução; a defesa intransigente dos direitos humanos contra todo tipo de arbítrio e autoritarismo; o aprofundamento e a consolidação da cidadania e da democracia; a defesa da socialização da participação política e da riqueza produzida; o posicionamento radical a favor da eqüidade e da justiça social, que implica a universalidade no acesso a bens e serviços e a sua gestão democrática; o empenho pela eliminação de todas as formas de preconceito, a garantia do pluralismo e o compromisso com a qualidade dos serviços prestados na articulação com outros profissionais e trabalhadores.

Menciona-se, ainda, outros pilares da profissão que vem sendo atualizados: a Lei de Regulamentação da Profissão, que representa a defesa da profissão na sociedade e situase como direção para a formação acadêmico-profissional, as diretrizes curriculares para a área do Serviço Social, propostas pela Associação Brasileira de Ensino e Pesquisa em Serviço Social -ABEPSS e aprovadas pelo Conselho Nacional de Educação e o documento do CFESS que trata sobre competências e atribuições privativas do assistente social.

Ao Serviço Social impõe-se o desafio de fortalecer sua identidade, seu ethos profissional, no tensionamento das relações na esfera da produção social - sociedade civil e Estado, espaço em que se situa o seu trabalho. Sem dúvida, são questões que traduzem exigências e requisições ao trabalho do Assistente Social ao mesmo tempo em que sinalizam novos espaços ocupacionais e de trabalho, que reeditam dilemas éticos presentes nas tensões historicamente enraizadas na constituição da profissão e nas estratégias de respostas a questão social (IAMAMOTO, 2003). Os processos societários contemporâneos

\begin{tabular}{llllll}
\hline Serviço Social \& Saúde & Campinas & v. 4 & n. 4 & p. 1-156 & Maio 2005 \\
\hline
\end{tabular}


vêm exigindo alterações tanto nos processos de formação profissional como nos enfoques políticos e éticos relativos aos mesmos.

O cenário atual é de muitas transformações e inquietações no que se refere aos rumos do ensino superior na América Latina. O sistema educacional não é poupado pela lógica mercantil disseminada em todo tecido social (CARDOSO, 2001), considerando-se sua importância na reprodução social. As atuais exigências derivadas destes processos de globalização trazem profundas alterações nos aspectos econômicos, culturais e sociais, com repercussões nas inter-relações globais e locais no mundo do trabalho e nos processos de inclusão e exclusão presentes na contemporaneidade. No Brasil, a reforma universitária, ora em curso, pressupõe ampliar e sedimentar o debate sobre a temática da formação profissional e seus espaços.

A intensa e recente expansão dos cursos de graduação do ensino privado, com expressando 75\% do número total de cursos criados nos últimos dois anos, tem sérias implicações para a política de formação profissional do assistente social. Esses novos cursos não acompanharam historicamente o processo coletivo de elaboração e implementação das diretrizes curriculares, exigindo da ABEPSS um trabalho de acompanhamento, monitoramento e de apoio às inúmeras demandas advindas deste processo. Esta predominância quantitativa exige dos órgãos de representação da categoria, conforme apontou Iamamoto (2004) em sua conferencia durante o IX ENPESS: "uma política específica de integração desses cursos e de qualificação dos quadros docentes, implementada regionalmente, aproximando-os dos fundamentos do projeto de formação profissional de que as diretrizes curriculares são expressão, como condição mesma de se preservar a direção social impressa ao ensino universitário na área, sua unidade $e$ qualidade do ensino".

Por outro lado às excessivas exigências decorrentes deste momento de expansão capitalista alteram a demanda de trabalho do assistente social, modificam o mercado de trabalho, alteram os processos e as condições de trabalho dos assistentes sociais, demarcando imensos desafios para a formação profissional. Este redimensionamento de exigências profissionais e da expansão recente da educação superior, segundo dados do INEP/MEC, também representa um forte impacto nas ações desenvolvidas pela ABEPSS.

\begin{tabular}{llllll}
\hline Serviço Social \& Saúde & Campinas & v. 4 & n. 4 & p. 1-156 & Maio 2005
\end{tabular} 
Estas transformações apresentam rebatimentos significativos em seu trabalho, que se consagrou ao longo de seus 56 anos, "produzindo os debates, chamando para o debate, construindo um espaço democrático para a discussão do Serviço Social” (CASSAB, 2002).

Por outro lado, as reformas do Estado vêm alterando significativamente as condições de trabalho, nas esferas pública e privada, com a extinção de postos de trabalho e serviços, demissões, contenção de salários, corrida à aposentadoria, aumento assustador dos índices de desemprego e de alta precarização das condições do exercício profissional. Os espaços ocupacionais sofrem significativas mutações trazendo imensos desafios.

Ampliam-se as exigências de estratégias políticas, clareza teórica e metodológica sobre as novas expressões da questão social, sobre as respostas sociais e profissionais, sobre as condições e relações laborais, a qualificação profissional, o exercício e as ações cotidianas. Atentos a tais exigências, os Assistentes Sociais sedimentam sua identidade profissional na contemporaneidade e, como diz Yasbeck (2003), tecendo-a no tempo miúdo do trabalho cotidiano.

Ressalta-se, portanto, que a reconstrução do projeto de formação profissional definiu-se, no Brasil, em um contexto sócio-político de implementação continuada, de mais de uma década, de uma política governamental orientada e prescrita por organismos multilaterais de fomento e financiamento, incidindo de forma contundente nos espaços de formação profissional. Apesar desse contexto, pode-se afirmar que o Serviço Social Brasileiro construiu uma proposta de revisão curricular que permite, hoje, discutir sua implementação sob uma base clara e consistente. Sustenta-se em uma proposta coletiva que não se encontra mais no campo das tendências, mas sim, na sustentação de um perfil profissional que busca ser coerente com o tempo presente na direção apontada pelo Código de Ética em vigor.

\section{BREVE RETROSPECTIVA HISTÓRICA}

Neste contexto, a ABEPSS, entidade nacional representativa das Instituições de Ensino Superior no âmbito do Serviço Social, atenta às necessidades da área, e contrapondo-se a lógica neoliberal, nos anos 90, promoveu um amplo debate e a avaliação dos impasses e tensões que compunham os desafios para a formação qualificada e eficiente

\begin{tabular}{llllll}
\hline Serviço Social \& Saúde & Campinas & v. 4 & n. 4 & p. 1-156 & Maio 2005
\end{tabular}


dos Assistentes Sociais, através da realização de mais de 200 oficinas. Este diagnóstico culminou com a realização de uma assembléia durante a XXIX Convenção Nacional da ABESS, em Recife, no ano de 1995. Naquele momento foi aprovada a proposta básica para o projeto de formação profissional contendo novo desenho curricular, embasado em diretrizes, pressupostos, núcleos de fundamentação ético-político, teórico-metodológico e técnico-operativo claramente delineados.

A concepção que informou as diretrizes é inspirada em uma tradição cultural que, ao privilegiar a história, reconhece não serem as categorias teóricas e analíticas fruto de uma formulação autônoma e aleatória do processo de viver e pensar. Ao contrário, aquelas categorias teóricas são entendidas como expressões, na esfera da razão, ”de modos de ser, determinações da existência” (MARX, 1974, p. 127), dadas na realidade efetiva.

A Proposta de Diretrizes Gerais para o Curso de Serviço Social apresentava-se como produto de um amplo e sistemático debate realizado pelas Unidades de Ensino, já a partir de 1994, quando a XXVIII Convenção Nacional da Associação Brasileira de Ensino de Serviço Social - ABESS, ocorrida em Londrina - PR, em outubro de 1993, deliberou sobre os encaminhamentos da revisão do Currículo Mínimo vigente desde 1982 (Parecer Conselho Federal de Educação no 412, de 04.08.1982 e Resolução n. ${ }^{\circ} 06$ de 23/09/82)

Entendendo que o processo de revisão curricular exigia uma profunda avaliação do processo de formação profissional face às exigências da contemporaneidade, a então $A B E S S$ (que posteriormente veio a constituir-se em ABEPSS) promoveu e coordenou com o Centro de Documentação e Pesquisa em Políticas Sociais e Serviço Social - CEDEPSS, órgão acadêmico que, na época, articulava a Pesquisa e a Pós-Graduação em Serviço Social, um intenso trabalho de mobilização das Unidades de Ensino de Serviço Social no país. Este processo de mobilização contou com o apoio decisivo da Entidade Nacional representativa dos profissionais de Serviço Social, através do Conselho Federal de Serviço Social CFESS, bem como, dos estudantes, através da Executiva Nacional dos Estudantes de Serviço Social - ENESSO.

Na etapa final do processo de revisão curricular as proposições do conjunto das Unidades de Ensino foram sistematizadas, resultando em seis documentos regionais a partir dos quais a Diretoria da ABESS, a representação da ENESSO e do CFESS, o Grupo de 
Consultores de Serviço Social e a Consultoria Pedagógica elaboraram a "Proposta Nacional de Currículo Mínimo para o Curso de Serviço Social”. Proposta esta apreciada e aprovada em Assembléia Geral da ABESS durante a II Oficina Nacional de Formação Profissional, realizada no Rio de Janeiro, em novembro de 1996.

Em 20 de dezembro de 1996 foi promulgada a nova Lei das Diretrizes e Bases da Educação Nacional - LDB - Lei 9394, tornando oportuno o processo de normatização e definição de Diretrizes Gerais para o Curso de Serviço Social no espírito da nova Lei. Tais Diretrizes tornam-se fundamentais para o estabelecimento de um patamar comum, assegurando, ao mesmo tempo, a flexibilidade, descentralização e pluralidade no ensino em Serviço Social, de modo a acompanhar as profundas transformações da ciência e da tecnologia na contemporaneidade.

A proposta, portanto, de acordo com as Diretrizes, foi a de resgatar as construções teórico-metodológicas a partir de uma compreensão do processo de

[...] constituição e desenvolvimento da sociedade burguesa, apreendida em seus elementos de continuidade e ruptura” [...]. A configuração da sociedade burguesa, nesta perspectiva, é tratada em suas especificidades quanto à divisão social do trabalho, à propriedade privada, à divisão de classes e do saber, em suas relações de exploração e dominação, em suas formas de alienação e resistência. Implica em reconhecer as dimensões culturais, ético-políticas e ideológicas dos processos sociais em seu movimento contraditório e elementos de superação (ABEPSS, 1997, pág. $64)$.

Conforme descreve o documento:

O pressuposto central das diretrizes é a permanente construção de conteúdos (teóricos, éticos, políticos, culturais) para a intervenção profissional nos processos sociais que são apreendidos de forma dinâmica, flexível, assegurando elevados padrões de qualidade na formação do assistente social (ABEPSS, 1997).

Conforme descreve o documento das diretrizes curriculares " $\mathrm{O}$ pressuposto central das diretrizes é a permanente construção de conteúdos (teóricos, éticos, políticos, culturais) para a intervenção profissional nos processos sociais que são apreendidos de

\begin{tabular}{llllll}
\hline Serviço Social \& Saúde & Campinas & v. 4 & n. 4 & p. 1-156 & Maio 2005 \\
\hline
\end{tabular}


forma dinâmica, flexível, assegurando elevados padrões de qualidade na formação do assistente social” (ABEPSS, 1997). Isto nos remete a um conjunto de conhecimentos indissociáveis, traduzidos nas diretrizes curriculares como núcleos de fundamentação: fundamentos teórico-metodológicos da vida social; fundamentos da formação sóciohistórica da sociedade brasileira e fundamentos do trabalho profissional.

\section{A FORMAÇÃO PROFISSIONAL NOS ANOS 2000 - CONSOLIDAÇÃO DO PROJETO ÉTICO-POLÍTICO E ARTICULAÇÃO GRADUAÇÃo E PÓS- GRADUAÇÃO}

Em consonância com os programas das gestões da ABEPSS, as ações se materializaram em dois planos e duas temporalidades.

Um plano que se direcionou a implementação e o fortalecimento das diretrizes curriculares, e que ocorreu nos últimos anos da década de 1990, com ênfase na produção difusão de conhecimentos relacionados ao Projeto de Formação Profissional. Como evidência e resultado dessa preocupação ocorreram as realizações das Oficinas Regionais e Nacionais, tendo como tema recorrente aspectos relacionados à discussão e assessoria para a implantação e sedimentação das diretrizes curriculares. No mesmo sentido houve a intensificação da publicação, através da Revista Temporalis, dois novos números foram publicados (7 e 8 da Temporalis) e foram reeditados 2 números que há muito estavam esgotados (1, 2 e 3) gerando grande demanda da comunidade acadêmica. Essas publicações foram construídas na perspectiva de reforçar o aporte teórico significativo na construção dos currículos.

Em época mais recente, a atual diretoria da ABEPSS amplia o foco da atenção para a articulação internacional, face às condições favoráveis e oportunas para tanto, sem descuidar da qualificação na formação profissional.

No primeiro foco e atendendo ao compromisso assumido na assembléia, realizada em Juiz de Fora, em novembro de 2002, iniciaram-se as tratativas para ampliação do debate sobre o envolvimento da ABEPSS com o Cone Sul e a Associación Latinoamericana de Trabajo Social - ALAETS. Buscando envolver e subsidiar o 
posicionamento das Unidades Acadêmicas sobre o tema, foi realizado o Seminário Latinoamericano de Serviço Social: articulação latino-americana e formação profissional. O objetivo central foi o de promover uma ampla discussão sobre a articulação e a inserção da ABEPSS na ALAETS.

Na ocasião, as Unidades de Ensino presentes decidiram por unanimidade que a ABEPSS caberia fortalecer os laços com o Cone Sul e assumir o papel de articuladora em relação a ALAETS, reafirmando a potencialidade do Projeto de Formação Profissional Brasileiro no âmbito da América Latina.

Como conseqüência desse propósito, ressalta-se a participação da ABEPSS no XVIII Seminário Latinoamericano de Escuelas de Trabajo Social, realizado em San José na Costa Rica, em julho de 2004. Durante o evento foi realizada uma Assembléia da ALAETS, que deliberou pela reestruturação da entidade em novas bases políticas, ideológicas e jurídicas. O Brasil, através da ABEPSS, compõe a Junta Diretiva, com os representantes do Equador e da Costa Rica. Esse grupo trabalha na perspectiva de realizar uma Assembléia da ALAETS a partir de uma proposta de sua refundação, lançando a direção política para que possamos avançar na direção deste processo de articulação do Serviço social na América Latina. A Junta Diretiva vem encaminhando este trabalho através da articulação junto às associações, profissionais e Unidades Acadêmicas.

Ainda no plano da articulação internacional, destaca-se a participação da ABEPSS, divulgando o trabalho e a forma de organização da Associação, contribuindo para o fortalecimento das entidades co-irmãs de outros países. As representações da ABEPSS estiveram em Portugal, a convite do Instituto Superior de Lisboa, na Argentina e na Costa Rica.

No segundo foco intensificou a discussão sobre uma das questões candentes na formação do Serviço Social, qual seja - o ensino do trabalho profissional. Nessa perspectiva, foram realizadas Oficinas descentralizadas nas Regionais da ABEPSS e duas Oficinas Nacionais.

Uma inovação, na Oficina de Florianópolis, foi a realização de assessorias para implementação das diretrizes curriculares, atendendo a uma antiga demanda das unidades de ensino. Outro aspecto inovador foi a inclusão na agenda da Oficina de temas relativos

\begin{tabular}{llllll}
\hline Serviço Social \& Saúde & Campinas & v. 4 & n. 4 & p. 1- 156 & Maio 2005 \\
\hline
\end{tabular}


especificamente aos Programas de Pós-graduação, buscando responder, de forma efetiva, a uma demanda tanto dos Programas como da plataforma da atual gestão da ABEPSS.

Uma das grandes preocupações da gestão atual foi buscar congregar as Unidades de Ensino associadas e procurar associar aquelas que não estavam vinculadas a ABEPSS. A expansão do ensino privado no Serviço Social, como de resto em todos os cursos universitários, é uma realidade que procuramos enfrentar, a partir da busca de capacitação dessas unidades de ensino quanto às diretrizes curriculares. A mobilização das Unidades para as Oficinas foi exitosa e teve resultados bastante positivos. O encaminhamento da gestão foi no sentido de romper com a dicotomia público/privada. Trabalhar na perspectiva da instrumentalização dos docentes das unidades privadas, na compreensão das diretrizes, bem como dar visibilidade aos tensionamentos próprios da estrutura do ensino privado.

Outro desafio enfrentado pela atual diretoria diz respeito a garantia da utilização das diretrizes curriculares na constituição do ENAD, no que diz respeito a comissão que elaborou as normas, que foi nomeada a partir das indicações das regionais da ABEPSS e contou com a confirmação dos nomes por parte do CFESS. A decisão da gestão de participar dessa comissão esteve respaldada na plataforma de eleição da gestão, onde se reafirmou o compromisso de assumir os espaços fundamentais para concretização das diretrizes curriculares aprovadas pela ABEPSS. A participação da comissão foi fundamental para que a avaliação fosse pautada nesses princípios. Avaliou-se nesse campo, o tensionamento que essa participação geraria, tanto do ponto de vista da discussão da preservação da luta pela universidade pública, laica e gratuita que foi sempre reafirmado nessa gestão, bem como do movimento legitimo das discentes, contrapondo-se a avaliação. A gestão da ABEPSS procurou deixar claro a todos os parceiros de que assumia essa tarefa como desafio, no intuito de criar oportunidade para debates com os órgãos do Ministério da Educação, visando abrir espaço para uma discussão pública sobre a necessidade de avaliação. Importante ressaltar o trabalho sério e competente dos Professores que assumiram a tarefa de dialogar, em nome de todos, nesse momento.

Ainda nesta mesma direção, a partir de junho de 2004 a ABEPSS começou a participar do Fórum dos Profissionais de Saúde. As discussões centravam-se inicialmente, na articulação destas áreas e na definição de quais profissões fazem parte de seu núcleo 
básico ou aquelas na qual a saúde é campo de atuação profissional. E, quase ao término da Gestão, novas e urgentes demandas do processo de mudanças implantadas pelo MEC, estavam sendo deflagradas. Desta vez, as mudanças atingiam a carga horária mínima dos cursos de Serviço Social. A proposta que seria votada pelo CNE previa uma redução significativa para os cursos de Serviço Social, que passariam de 3200 horas/ aulas para 2400 horas/ aula. A articulação nacional da qual participaram docentes, discentes, CFESS, ENESSO e toda diretoria da ABEPSS tiveram como resultado final à aprovação de 3000 horas/aula para a área. Ressalte-se que a PUC/SP teve uma participação importante, através da direção do curso de Serviço Social, da vice-presidente da região e de seu reitor.

Cabe ressaltar que o boletim informativo da ABEPSS, criado nesta gestão foi uma das estratégias de gestão que possibilitou levar noticias, aproximar Unidades de Ensino, dar retorno mensal do trabalho que a equipe desenvolvia.

Neste contexto é importante destacar, que dentro dos princípios que norteiam o processo de consolidação do Projeto Ético Político do Serviço Social Brasileiro, muitas atividades foram realizadas em conjunto com o CFESS e com a ENESSO, fortalecendo a articulação entre as entidades representativas e dando materialidade ao projeto. Dentre elas, destaca-se a segunda edição do Curso a Distância, no qual foi introduzido um módulo específico para docentes, buscando atender a uma demanda evidenciada desde a realização do primeiro curso. Esse trabalho envolveu as duas direções, da ABEPSS e do CFESS, durante todo o ano de 2004, sendo consolidado com o lançamento do curso em outubro do mesmo ano, durante o XI Congresso Brasileiro de Serviço Social e III Encontro Nacional de Serviço Social na Esfera da Seguridade Social. Em relação a esses dois eventos, a ABEPSS trabalhou desde a concepção dos mesmos, em conjunto com as demais entidades da categoria (CFESS e ENESSO). A coordenação da Comissão Científica, embora compartilhada, ficou sob responsabilidade da equipe diretiva da ABEPSS que participou a seleção dos trabalhos, apresentando, indicando pareceristas, como também da constituição das mesas dos eventos.

Com estas inúmeras atividades desenvolvidas, através das muitas frentes e demandas a equipe buscou garantir e contribuir no sentido de que a formação da graduação e pós-graduação em Serviço Social cada vez mais pudesse substanciar e respaldar a

\begin{tabular}{llllll}
\hline Serviço Social \& Saúde & Campinas & v. 4 & n. 4 & p. 1-156 & Maio 2005 \\
\hline
\end{tabular}


plataforma emancipatória da profissão, na resistência às mais diversas formas de exclusão, opressões e violências que, no tempo presente, se adensam e atualizam como demanda privilegiada ao ensino de qualidade e à pesquisa no Serviço Social.

O desafio para os Assistentes Sociais é o de uma tomada de posição ética e política que se insurja contra os processos de alienação vinculados à lógica contemporânea, impulsionando-nos a dimensionar nosso processo de trabalho na busca de romper com a dependência, subordinação, despolitização, construção de apatias que se institucionalizam e se expressam em nosso cotidiano de trabalho.

O desafio maior com o qual nos defrontamos é o de avançarmos na consolidação e implementação do projeto profissional, inscrevendo seus princípios em nosso cotidiano de trabalho. Embora reconheçamos as adversidades do contexto, de modo contraditório, este mesmo contexto, como bem destaca Iamamoto, que impulsionam e mantém vivas as forças sociais portadoras da esperança e da capacidade de lutas na arena social e profissional.

Essa contradição pode ser visualizada na realização do IX ENPESS (novembro de 2004, PUCRS). As pesquisas apresentadas, os debates realizados, caracterizados pela grande criatividade e seriedade acadêmica, mostraram que os tempos adversos também têm contribuído para que docentes, discentes e assistentes sociais estejam atentos às demandas contemporâneas para o Serviço Social, procurando explicá-las e buscando respostas que reafirmem o projeto ético político da profissão.

Para a ABEPSS fica a necessidade de buscar refletir sobre seu trabalho, sua organização uma vez que a equipe ao assumir esta responsabilidade plena de desafios deve dispor de condições concretas para sua realização. As responsabilidades docentes continuam em uma dupla jornada, trazendo a marca da mercantilização, que pauta critérios, padrões e orientações institucionais que capturam todas nossas possibilidades objetivas de trabalho diante de tantas demandas.

Assim, o caminho percorrido - com conquistas e sobressaltos - produto de um vigoroso projeto, que buscou reunir condições para garantir a direção, o norte, à bússola que não abdica dos debates acadêmicos, mas que os enfrenta com a certeza de que temos algo construído que nos une, na defesa de uma sociedade mais justa.

\begin{tabular}{llllll}
\hline Serviço Social \& Saúde & Campinas & v. 4 & n. 4 & p. 1-156 & Maio 2005
\end{tabular} 


\begin{abstract}
This article deals with the Brazilian Teaching and Research Social Work Association role in the professional education, specially regarding the new requirements established for college education in the globalization process. The importance of the General Guidelines of the Social Work Course in the Professional Project in Brazil is reinforced.
\end{abstract}

KEY-WORDS: Professional Education, Curriculum Guidelines, ABEPSS, Professional Project.

\title{
REFERÊNCIAS BIBLIOGRÁFICAS
}

ABESS/CEDEPSS. Formação Profissional: Trajetória e Desafios. Diretrizes Gerais para o Curso de Serviço Social (Com base no currículo mínimo aprovado em Assembléia Geral Extraordinária de oito de novembro de 1996). Cadernos ABESS. São Paulo: Cortez, 1997. n. 7.

CARDOSO, M. L. Avaliação da universidade: Legitimação e Lógica Mercantil. Temporalis, Brasília. Revista da Associação Brasileira de Ensino e Pesquisa em Serviço Social. Ano 2, Suplemento, 2001.

IAMAMOTO, M. V., CARVALHO. R. Relações Sociais e Serviço Social no Brasil. 10. ed. São Paulo: Cortez/ Celats, 1995.

IAMAMOTO, M. V. O Serviço Social na contemporaneidade: trabalho e formação profissional, São Paulo: Cortez, 1998.Cap. I e II

Projeto profissional, espaços ocupacionais e trabalho do assistente social na atualidade. DF: CFESS, 2002.

MARX, K. Prefácio à Contribuição à Crítica da Economia Política. In: Marx. Coleção Os Pensadores. São Paulo: Vítor Civita, 1974.

YASBECK, M. C. Pobreza e Exclusão Social: Expressões da Questão Social no Brasil. In: Temporalis, Brasília. Revista da Associação Brasileira de Ensino e Pesquisa em Serviço Social, ano 2, no 3, jan. a jun. de 2001.

\begin{tabular}{llllll}
\hline Serviço Social \& Saúde & Campinas & v. 4 & n. 4 & p. 1-156 & Maio 2005 \\
\hline
\end{tabular}




\section{BIBLIOGRAFIA CONSULTADA}

ABESS/CEDEPSS. Proposta Básica para o Projeto de Formação Profissional. Revista Serviço Social \& Sociedade, São Paulo: Cortez, n. 50, abril de 1996.

ALMEIDA, N. L. T. Considerações para o exame do processo de trabalho do Serviço Social. Serviço Social \& Sociedade, São Paulo: Cortez, n. 52, p.7-23, dez. 1996.

ALMEIDA, N. L. T. (Coord.) Reflexões Iniciais sobre a Construção do Novo Currículo Pleno do Curso de Serviço Social da FSS/UERJ. PEEPSS/FSS/UERJ, mimeo, agosto de 1999.

BARBOSA, R. N. B., CARDOSO, F. G. e ALMEIDA, N. L. A categoria 'processo de trabalho' e o trabalho do Assistente Social. Serviço Social \& Sociedade, São Paulo: Cortez no 58, p. 109-130, nov. 1998.

BEHRING, E. R., CARDOSO, I., GRANEMAN, S., IAMAMOTO, M. e TEIXEIRA, N. L. Currículo Mínimo: Novos subsídios para o debate. Cadernos ABESS, São Paulo: ABESS/Cortez, n. 7. 1997.

BEHRING, E. R. Brasil em Contra-Reforma: desestruturação do Estado e perda de direitos. São Paulo: Cortez, 2003.

CASSAB, M. A T., BATISTONI, M. R. Proposta de Criação de Curso de graduação em Serviço Social - USP. Temporalis. Brasília. Revista da Associação Brasileira de Ensino e Pesquisa em Serviço Social. Ano 3, Suplemento, ABEPSS, novembro de 2002.

CFESS. Código de Ética do Assistente Social. Brasília, 1993.

GRANEMANN, S. Processos de trabalho e Serviço Social. CFESS-ABEPSS-CEAD/UNB. Reprodução Social, Trabalho e Serviço Social. Módulo I. Capacitação em Serviço Social e Política Social. Brasília: CEAD, 1999.

GUERRA, Y. Instrumentalidade do processo de trabalho e Serviço Social. Serviço Social \& Sociedade, São Paulo: Cortez, n. 62, 2000.

LESSA, S O processo de produção/ reprodução social: trabalho e sociabilidade. CFESSABEPSS-CEAD/UNB. Crise Contemporânea, Questão Social e Serviço Social. Módulo I. Capacitação em Serviço Social e Política Social. Brasília: CEAD, 1999. . Serviço Social e trabalho: do que se trata? Temporalis, Brasília: ABEPSS, n. 2, 2000.

\begin{tabular}{llllll}
\hline Serviço Social \& Saúde & Campinas & v. 4 & n. 4 & p. 1-156 & Maio 2005 \\
\hline
\end{tabular}


MOTA. A E. (Org). A Nova Fábrica de Consensos. São Paulo: Cortez, 1998.

PAULO NETTO, J. Teoria, Método e História na Formação Profissional. Cadernos ABESS, São Paulo: Cortez, n. 1, 1986.

. Crise do Socialismo e Ofensiva Neoliberal. São Paulo: Cortez, 1993.

SERRA, R. M Crise de materialidade no Serviço Social; repercussões no mercado profissional, São Paulo: Cortez, 2000.

- A processualidade do Serviço Social crítico no Brasil em tempos de reestruturação produtiva. Em Pauta, Rio de Janeiro: UERJ, n. 15, jul. /dez. 1999.

SILVA A C. A Presença da Universidade Pública. Comissão de Defesa da Universidade Pública - IEE - USP - 2000. Internet. 
